\title{
Peningkatan Kapasitas Produksi dan Inovasi Produk Kelompok Usaha Bersama Cempaka di Desa Tambaksogra Kabupaten Banyumas
}

\author{
Bambang Agus Pramuka1*, Sugiarto², Poppy Dian I.K ${ }^{3}$ \\ 1,2,3 Jurusan Akuntansi , Fakultas Ekonomi dan Bisnis, Universitas Jenderal Soedirman, Purwokerto, \\ Indonesia \\ *Penulis korespondensi, email: bpramuka@gmail.com
}

\section{Submit : \\ 1 Des 2019 \\ Diterima: \\ 10 Des 2019 \\ Terbit:}

20 Des 2019

\begin{abstract}
Abstrak. Kegiatan ini bertujuan untuk mengembangkan kapasitas produksi dua kelompok usaha mikro yang memproduksi makanan ringan di Dusun Kalisogra Kabupaten Banyumas, yaitu Kelompok Usaha Bersama (KUB) Cempaka dan Melati. Permasalahan yang dihadapi KUB Cempaka yang memproduksi kripik pisang yaitu dapur produksi belum higienis karena berlantai tanah, ukuran dan rasa kripik belum standar, kemasan belum standar karena masih menggunakan stapler, variasi rasa produk masih terbatas belum memiliki sarana transportasi, belum memiliki spinner untuk mengurangi kadar minyak kripik untuk menjaga daya tahan, belum memiliki jaringan untuk pasokan bahan baku pisang, belum memiliki media pemasaran, belum memiliki ijin kesahan dari Dinas Kesehatan yaitu Pangan Industri Rumah Tangga (PIRT). Metode yang digunakan adalah ceramah, pelatihan dan pendampingan di lokasi kegiatan. Hasilnya adalah peningkatan higienitas dapur produksi yang berdampak pada kualitas produk dan kepuasan anggota yang bekerja di dapur, ukuran kripik yang standar karena dipotong menggunakan alat, kemasan yang menarik dapat meningkatkan harga jual produk, variasi rasa dapat meningkatkan pangsa pasar, penggunaan spinner untuk mengurangi kadar minyak sehingga kripik lebih tahan lama, pengurusan ijin kesahan PIRT memberikan jaminan kepada pembeli akan mutu produk serta tidak perlu khawatir produk akan disita jika ada inspeksi dari Dinas Kesehatan karena produk dianggap tidak legal.
\end{abstract}

Kata Kunci: kapasitas produksi, kripik, bahan baku local, Banyumas 


\section{Pendahuluan}

Kelompok Usaha Bersama (KUB) Cempaka adalah kelompok ibu-ibu yang berada di wilayah barat dusun Kalisogra. Kelompok ini beranggotakan 5 orang yang di ketuai oleh ibu Soviyah. Produksi keripik pisang Cempaka ini dilakukan di sebuah rumah bertempat di Perumahan Dusun Tambak Sogra Rt 02 Rw 05 Kec Sumbang Purwokerto. Disini, rumah produksi merupakan rumah pribadi dari ketua PKK Cempaka sebagai tempat produksi, karena memang tujuan awal adalah kegiatan Home Industri. Pembuatan produk ini tidak begitu sulit, karena bahan mudah didapatkan dan tidak membutuhkan terlalu banyak proses. Proses pembuatan kripik pisang membutuhkan bahan utama pisang dan minyak goreng serta bahan pembantu yang terdiri dari gula, garam. Selain itu, untuk memproduksinya juga membutuhkan peralatan seperti pisau, alat pemasrah/pemotong, baskom, wajan, serok dan susuk, serta nampan. Kripik ini memiliki keunikan dibandingkan dengan kripik lainnya dalam hal rasa karena bahan baku yang digunakan hasil panen hari itu juga dan langsung diproses di hari yang sama. Kelebihan lainnya adalah kripik ini tidak menggunakan bahan pengawet tetapi menggunakan garam dan gula saja sebagai perasa. Permintaan kripik pisang cempaka sangat tinggi, hasil produksi langsung dijual ke pelanggan di hari yang sama sehingga KUB Cempaka tidak mempunyai stok barang. Kemampuan produksi saat ini masih terbatas sejumlah 2 tundun per hari karena terbatasnya ketersediaan bahan baku. Sebenarnya kelompok mampu memproduksi sebanyak 10 tundun per hari jika bahan baku tersedia. Berikut adalah analisis keuntungan KUB Cempaka. Pendapatannya berasal dari perhitungan berikut:

$$
\begin{aligned}
& \begin{aligned}
\text { Pendapatan } & =\text { Unit penjualan } \times \text { harga jual } \\
& =1500 \times \text { Rp. } 5.000=\text { Rp. } 7.500 .000
\end{aligned} \\
& \begin{aligned}
\text { Total biaya produksi dalam } 1 \text { bulan } \quad \text { : Rp. } 4.482 .000 \\
\text { Keuntungan }=\text { pendapatan }- \text { total biaya produksi } \\
=\text { Rp. } 7.500 .000-\text { Rp. } 4.482 .00=\text { Rp. } 3.018 .000
\end{aligned}
\end{aligned}
$$

Permasalahan lain yang dihadapi KUB Cempaka yang memproduksi kripik pisang yaitu dapur produksi belum higienis karena berlantai tanah, ukuran dan rasa kripik belum standar, kemasan belum standar karena masih menggunakan stapler atau lilin untuk menyegel plastic kemasan, variasi rasa produk masih terbatas, belum memiliki sarana transportasi, belum memiliki spinner untuk mengurangi kadar minyak kripik untuk menjaga daya tahan, belum memiliki jaringan untuk pasokan bahan baku pisang, belum memiliki media pemasaran, belum memiliki ijin kesahan dari Dinas Kesehatan yaitu Pangan Industri Rumah Tangga (PIRT). Prioritas masalah yang akan diatasi yaitu dapur produksi belum higienis karena berlantai tanah, ukuran dan ketebalan kripik serta rasa yang belum standar, kemasan belum standar karena masih menggunakan stapler atau lilin untuk penyegelan, variasi rasa produk masih terbatas, belum memiliki sarana transportasi, belum memiliki spinner untuk mengurangi kadar minyak kripik untuk menjaga daya tahan, belum memiliki jaringan untuk pasokan bahan baku pisang, pembuatan media pemasaran online, pengurusan ijin kesahan dari Dinas Kesehatan yaitu Pangan Industri Rumah Tangga (PIRT). Manfaat yang diharapkan adalah peningkatan higienitas dapur produksi yang berdampak pada 
kualitas produk dan kepuasan anggota yang bekerja di dapur, ukuran kripik yang standar karena dipotong menggunakan alat, kemasan yang menarik dapat meningkatkan harga jual produk, variasi rasa dapat meningkatkan pangsa pasar, penggunaan spinner untuk mengurangi kadar minyak sehingga kripik lebih tahan lama, pengurusan ijin kesahan PIRT memberikan jaminan kepada pembeli akan mutu produk serta tidak perlu khawatir produk akan disita jika ada inspeksi dari Dinas Kesehatan karena produk dianggap tidak legal. Berikut adalah profil kelompok pengrajin KUB Cempaka.

\section{METODE}

Dalam pelaksanaan proyek pengabdian ini, selain berdiskusi dengan mitra, tim selalu berkonsultasi secara intensif dengan pemerintah Desa Tambaksogra sebagai salah satu Pembina KUB Cempaka. Untuk mengatasi permasalahan yang berkaitan dengan infrastruktur, telah dilakukan rehabilitasi atau pembangunan fasilitas yang diperlukan. Untuk masalah kekurangan peralatan produksi, akan dilakukan pengadaan alat produksi yang dimaksud. Permasalahan yang berkaitan dengan ketiadaan keterampilan, akan diatasi dengan pelatihan dan pendampingan.

\subsection{Prosedur Kerja dan Partisipasi Mitra dalam Pelaksanaan Program}

\subsubsection{Perbaikan dapur}

Sesuai kesepakatan, akan dilakukan perbaikan dapur agar sesuai standar Dinas Kesehatan. Pembelian bahan bangunan akan dibebankan kepada tim pengabdian pihak KUB akan memberikan kontribusi berupa penyediaan konsumsi bagi tenaga kerja/ tukang yang melakukan renovasi dapur. Hasil perbaikan dapur diharapkan mampu meningkatkan rasa nyaman anggota dalam berproduksi serta keamanan produk dari berbagai bentuk kontaminasi yang tidak diinginkan.

\subsubsection{Perbaikan kapasitas dan kualitas produksi}

Untuk meningkatkan kapasitas produksi, tim akan membelikan alat pemotong pisang agar hasil ukuran kripik standar. Anggota KUB akan diberikan pelatihan terkait cara mengoperasikan mesin, serta pemeliharaan mesin agar tetap bersih dan awet. Penggunaan mesin ini akan dilengkapi dengan meja khusus yang memungkinkan hasil irisan pisang langsung masuk ke penggorengan agar tidak lengket.

\subsubsection{Perbaikan kemasan}

Tim akan mendesain kemasan yang menarik dengan kualitas plastik sesuai standar kesehatan. Tim akan memproduksi 1000 eksemplar label dan kemasan yang dapat digunakan oleh KUB Cempaka. Hasil perbaikan ini diharapkan mampu memperluas akses pasar kripik cempaka hingga ke outlet-outlet pusat oleh-oleh khas Purwokerto dan berbagai supermarket diwilayah purwokerto.

\subsubsection{Pembuatan pemasaran online}

media

Desain pemasaran online akan didesain oleh tim IbM, akan tetapi sebelum launching tim akan mendiskusikan terlebih dahulu dengan anggota KUB Cempaka terkait desain pemasaran online. Komunikasi ini penting untuk dilakukan karena berdampak terhadap kesiapan anggota kelompok untuk memanfaatkan media tersebut pasca pembuatannya.

\subsubsection{Pengurusan PIRT}

Pada tahap awal tim akan memberikan sosisalisasi terkait PIRT dan manfaatnya bagi keberlangsungan usaha KUB Cempaka. Selanjutnya pendampingn akan dilakukan terkait pengurusan PIRT sampai ijin keluar dari Dinas Kesehatan Kabupaten Banyumas. 
3. HASIL DAN PEMBAHASAN

3.1 Analisis SWOT

Untuk mengidentifikasi kebutuhan pendampingan pada KUB Cempaka telah dilakukan analisis SWOT sebagai berikut:

\begin{tabular}{|c|c|}
\hline $\begin{array}{l}\text { STRENGHS } \\
\text { - Berpengalaman dalam kualitas rasa } \\
\text { - Tanpa pengawet } \\
\text { - Kualitas pisang baik } \\
\text { - Demand tinggi } \\
\text { - Harga relatif murah } \\
\text { - Dana tersedia } \\
\text { - Dekat dengan lokasi bahan baku }\end{array}$ & 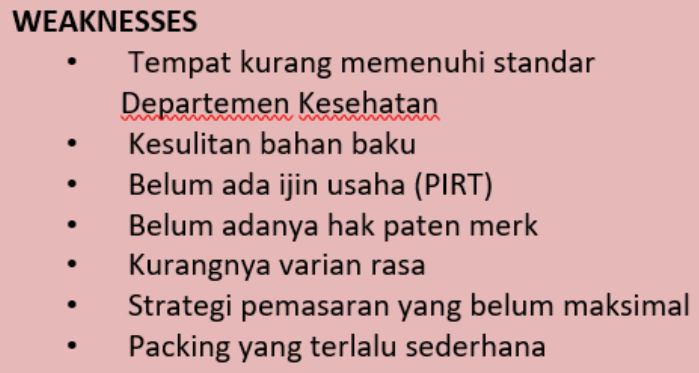 \\
\hline $\begin{array}{l}\text { OPPORTUNITIES } \\
\text { - } \quad \text { Pasar yang terbuka } \\
\text { - } \quad \text { Menjaga mutu dan kualitas } \\
\text { - Produk dapat bersaing dengan industri } \\
\text { lain yg skalanya lebih tinggi }\end{array}$ & $\begin{array}{l}\text { THREATS } \\
\begin{array}{l}\text { - Peluang kompetitor tinggi } \\
\text { - modal usaha kecil } \\
\text { - Banyaknya produsen kripik pisang }\end{array}\end{array}$ \\
\hline
\end{tabular}

Gambar 1. SWOT analysis KUB Cempaka
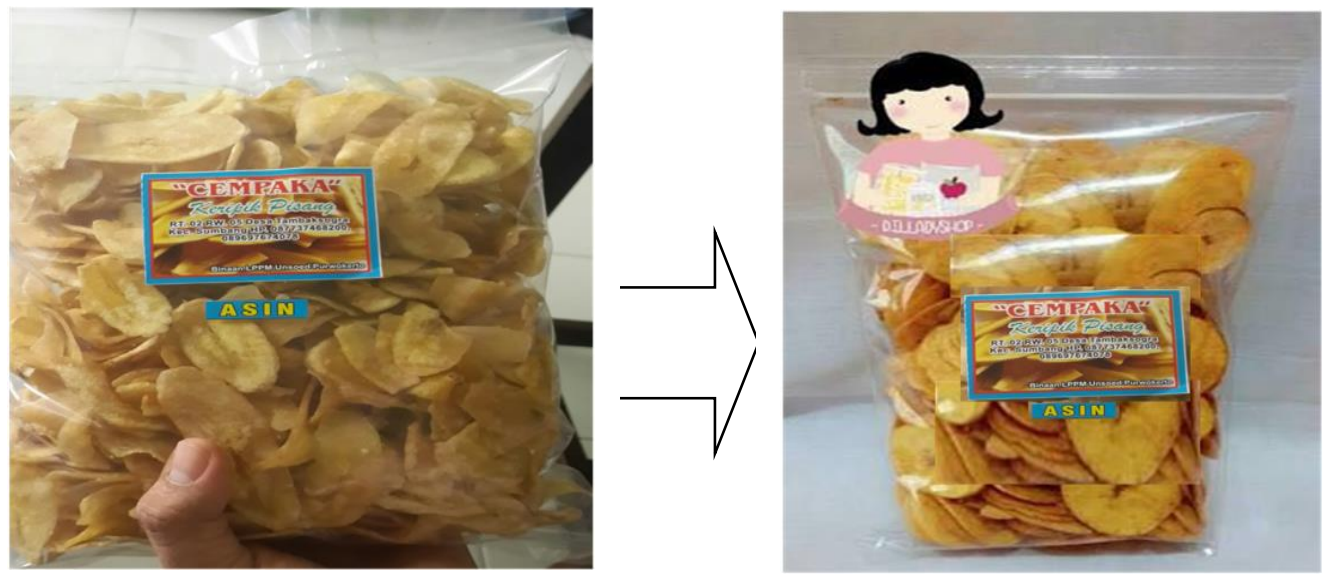

Gambar 2. Perubahan Kemasan

\subsection{Luaran Pendampingan}

Tim bekerjasama dengan IKM di desa Pasir Wetan mengembangkan alat pemotong kripik agar ukuran kripik pisang yang dihasilkan konsisten setiap saat. Alat ini memiliki kecepatan dalam pengirisan juga sepuluh kali lebih cepat dibandingkan dengan pisau pemotong manual. Penggunaan alat ini juga dilengkapi dengan desain meja yang praktis agar hasil potongan pisanga dapat langsung masuk ke penggorengan. Berikut adalah contoh mesin pemotong pisang untuk meningkatkan kapasitas produksi.

Aspek berikutnya yang akan diperbaiki adalah kemasan. Perbaikan kemasan ini sangatlah penting untuk meningkatkan nilai jual kripik. Kemasan yang akan digunakan dibuat lebih menarik dengan harga terjangkau. Kemasan yang digunakan saat ini masih belum standar karena masih menggunakan stapler atau lilin untuk penyegelan dan plastic yang digunakanpun belum sesuai standar. Kemasan yang akan 
diusulkan berupa kemasan dengan posisi standing untuk meningkatkan daya tarik produk jika akan dipasarkan ke supermarket. Berikut adalah perubahan kemasan agar lebih menarik untuk produk kripik pisang buatan KUB Cempaka (Gambar 2).

Mitra KUB Cempaka akan diberikan pelatihan dan pendampingan terkait proses pengemasan yang higinis misalkan menggunakan sarung tangan saat memasukkan kripik pisang ke dalam plastik kemasan, tidak menggunakan kertas koran untuk mengeringkan minyak setelah kripik di angkat dari penggorengan. Alat produksi yang digunakan di dapur masih belum sesuai standar kesehatan sementara PIRT/ BPOM mensyaratkan agar semua peralatan produksi terbuat dari logam agar mudah dibersihkan. Misalkan alat peniris minyak/ serokan terbuat dari bambu, alas kripik menggunakan tampah sebelum dimasukkan ke dalam plastik. Pelatihan tentang cara meningkatkan variasi rasa produk masih terbatas serta tim akan membelikan spinner untuk mengurangi kadar minyak kripik untuk menjaga daya tahan. Berikut adalah contoh desain alat produksi yang sesuai dengan standar BPOM.

Tim pengabdian telah mengembangkan jaringan pasokan bahan baku karena saat ini bahan baku pisang masih sangat terbatas sehingga mempengaruhi produksi. Tim akan memberikan pelatihan tentang pembuatan alternatif kripik menggunakan bahan baku temped dan sayuran sebagai alternatif produk untuk mengatasi permasalahan keterbatasan bahan baku pisang.

Luaran pelatinan pemasaran online berupa facebook, Instagram, blackberry messanger dan whatsapp untuk memasarkan produk kripik Cempaka. Hasil pendampinan pengurusan ijin PIRT adalah terbitnya ijin PIRT bagi produk KUB Cempaka. Hasil pelatihan tentang cara menghitung harga pokok produksi dan pembukuan sederhana berupa teknologi tepat guna tentang cara perhitungan harga pokok produksi. Ringkasan hasil luaran kegiatan pendampingan dapat dilihat pada Tabel 1.

Tabel 1 Target Capaian Luaran kegiatan

\begin{tabular}{|c|c|c|}
\hline No & Jenis Luaran & Indikator Capaian \\
\hline 1 & $\begin{array}{l}\text { Publikasi ilmiah di jurnal/ } \\
\text { prosiding }\end{array}$ & $\begin{array}{l}\text { Terdiseminasinya kegiatan pengabdian } \\
\text { masyarakat di desa Tambaksogra }\end{array}$ \\
\hline 2 & Pembuatan kemasan & $\begin{array}{l}\text { Adanya label dan kemasan baru untuk KUB } \\
\text { Cempaka }\end{array}$ \\
\hline 3 & Perbaikan dapur & $\begin{array}{l}\text { Meningkatnya kapasitas produksi dan rasa } \\
\text { nyaman anggota KUB saat bekerja }\end{array}$ \\
\hline 4 & $\begin{array}{l}\text { Pelatihan dan pendampingan } \\
\text { pemasaran online }\end{array}$ & $\begin{array}{l}\text { Launching media promosi online } \\
\text { menggunakan intagram, dan facebook }\end{array}$ \\
\hline 5 & $\begin{array}{l}\text { Pendampingan perhitungan } \\
\text { harga pokok produksi dan } \\
\text { pelaporan keuangan }\end{array}$ & $\begin{array}{l}\text { Teknologi tepat guna tentang Manajemen } \\
\text { Keuangan UMKM }\end{array}$ \\
\hline 6 & Peningkatan Omzet Mitra & $\begin{array}{l}\text { Terjadi pertumbuhan penjualan sebesar } 20 \\
\text { persen setiap bulannya. }\end{array}$ \\
\hline 7 & $\begin{array}{l}\text { Pengadaan alat produksi dan } \\
\text { pelatihan tentang kualitas } \\
\text { produksi }\end{array}$ & $\begin{array}{l}\text { Meningkatnya pengetahuan anggota tentang } \\
\text { proses produksi dan kemasan yang higinis }\end{array}$ \\
\hline 8 & Pengurusan ijin PIRT & $\begin{array}{l}\text { - KUB Cempaka sudah memiliki PIRT } \\
\text { - Meningkatkan rasa aman akan } \\
\text { konsumen akan produk KUB Cempaka }\end{array}$ \\
\hline
\end{tabular}




\section{KESIMPULAN}

Kegiatan pelatihan dan pendampingan terkait proses pengemasan yang higinis misalkan menggunakan sarung tangan saat memasukkan kripik pisang ke dalam plastik kemasan, tidak menggunakan kertas koran untuk mengeringkan minyak setelah kripik di angkat dari penggorengan terbukti mampu meningkatan kapasitas dan mutu produksi KUB Cempaka. Tim pengabdian telah membentuk jaringan pasokan bahan baku karena saat ini bahan baku pisang masih sangat terbatas sehingga mempengaruhi produksi. Untuk pemasaran online tim memberikan pelatihan untuk pemasaran menggunakan facebook, Instagram, dan whatsapp serta pembuatan profil KUB Cempaka untuk diupload di facebook. Seluruh kegiatan telah meningkatkan penjualan kripik.

\section{Ucapan Terimakasih}

DRPM Dikti, LPPM Universitas Jenderal Soedirman, dan KUB Cempaka.

\section{DAFTAR PUSTAKA}

Abdullah, Burhanuddin. Menanti Kemakmuran Negeri: Kumpulan Esai tentang Pembangunan Sosial Ekonomi Indonesia. Jakarta: Gramedia Pustaka Utama, 2006.

Ahman, Eeng dan Epi Indriani. Membina Kompetensi Ekonomi. Bandung: Grafindo Media Pratama, 2007.

Antonio, Muhammad Syafi'i. Bank Syariah: dari Teori ke Praktik. Jakarta: Gema Insani, 2001.

Christiaensen, L., Hoddinott, J., \& G. Bergeron, G., 2001, Comparing village characteristics derived from rapid appraisals and household surveys: A tale from northern Mali, Journal of Development Studies, Volume 37, Issue 3, pages 1-20

Dimyati, Khudzaifah. "Profil Pelepas Uang (Rentenir) dalam Masyarakat Transisi: Studi Kasus di Kartasura Kabupaten Sukoharjo" (Tesis-Universitas Diponegoro, Semarang, 1997).

Dwiono, Abu Muhammad. Selamat Tinggal Bank Konvensional. Jakarta: Tifa Publishing House, 2011. 